\title{
Factors influencing the likelihood of vacuum delivery success
}

\author{
Kunaal K. Shinde*, Anand Karale, Gulabsingh Shekhawat
}

Department of Obstetrics and Gynecology, Smt. Kashibai Navale Medical College and General Hospital, Narhe, Pune, Maharashtra, India

Received: 17 July 2017

Accepted: 22 July 2017

\section{*Correspondence:}

Dr. Kunaal K. Shinde,

E-mail: dr.kunaal.shinde@gmail.com

Copyright: () the author(s), publisher and licensee Medip Academy. This is an open-access article distributed under the terms of the Creative Commons Attribution Non-Commercial License, which permits unrestricted non-commercial use, distribution, and reproduction in any medium, provided the original work is properly cited.

\section{ABSTRACT}

Background: Instrumental or assisted vaginal birth is commonly used to expedite birth, for the benefit of either mother, baby or both. Objective of present study was to evaluate risk factors for unsuccessful vacuum delivery when variability between individual accoucheurs is taken into account.

Methods: We conducted a retrospective cohort study of attempted 687 vacuum deliveries over a 10-year period (2008-2017 inclusive) in a tertiary care center at Smt. Kashibai Navale Medical College and General Hospital, Narhe to account for inter-accoucheur variability, we matched unsuccessful deliveries (cases) with successful deliveries (controls) by the same operators. Multivariate logistic regression was used to compare successful and unsuccessful vacuum deliveries.

Results: During the study period of 10 years, there were 29861 deliveries, of which $19831(66.4 \%)$ were vaginal deliveries. $8802(29.47 \%)$ were cesarean deliveries and $1228(4.1 \%)$ were instrumental deliveries. Among instrumental deliveries, $687(56 \%)$ were vacuum deliveries and $541(44 \%)$ were forceps deliveries. Six hundred and eighty-seven ventouse deliveries of vertex presenting, single, term infants were attempted, of which 38 were unsuccessful $(5.5 \%)$. Increased birth weight $(\mathrm{OR}=1.11 \mathrm{p}<0.001)$, second-stage duration $(\mathrm{OR}=1.01 \mathrm{p}<0.001)$, rotational delivery $(\mathrm{OR}=1.52 \mathrm{p}<0.05)$ and use of ventouse versus forceps $(\mathrm{OR}=1.33 \mathrm{p}<0.05)$ were associated with unsuccessful outcome. When inter-accoucheur variability was controlled for, instrument selection and decision to rotate were no longer associated with vacuum delivery success. More senior accoucheurs had higher rates of unsuccessful deliveries $(12 \%$ v. $5 \%, \mathrm{p}<0.05)$, but undertook more complicated cases. Cesarean delivery in the second stage without prior attempt at ventouse delivery was associated with higher birth weight $(\mathrm{OR}=1.07 \mathrm{p}<0.001)$, increased maternal age $(\mathrm{OR}=1.03 \mathrm{p}<0.01)$, and epidural analgesia $(\mathrm{OR}=1.46 \mathrm{p}<0.001)$.

Conclusions: Careful selection of cases and adequate training of post graduate students during residency under direct supervision of senior experienced obstetrician can reduce the rate of failed vacuum delivery and related complications Results suggest that birth weight and head position are the most important factors in successful vacuum delivery, whereas the influence of patient selection and rotational delivery appear to be operator-dependent. Risk factors for lack of vacuum delivery success are distinct from risk factors for requiring vacuum delivery, and these should not be conflated in clinical practice.

Keywords: Birth trauma, Instrumental delivery, Perineal tear, Still births, Vacuum delivery, Ventouse

\section{INTRODUCTION}

Instrumental or assisted vaginal birth is commonly used to expedite birth, for the benefit of either mother, baby or both. ${ }^{1}$ Between 5 and $20 \%$ of infants are delivered by instrumental (operative vaginal) delivery in developed countries and $4.4 \%$ in our center. ${ }^{1}$ Overall, approximately $5-10 \%$ of attempted ventouse deliveries will fail ${ }^{2}$. 
Unsuccessful attempts are associated with a higher risk of adverse maternal outcomes than proceeding directly to cesarean delivery, including increased rates of general anesthetic and wound infection, as well as psychological trauma. Women who have had a previous failed attempt are likely to opt for an elective repeat cesarean delivery rather than another attempted vaginal birth. There are widespread procedural variations in assisted vaginal birth that depend on many factors. Operator choice is foremost among these, and this in itself is governed by the clinical scenario, local practice, geographical location, and occasionally consumer preference. The clinical indications for an assisted birth take into account maternal and fetal wellbeing. Maternal indications include exhaustion following prolonged labor, failure to progress in the second stage of labor, and medical conditions such as preeclampsia, placental abruption, or acquired or congenital heart disease. Fetal indications are fetal distress in the second stage of labor either due to the maternal condition or occurring independently of it. Other factors which must be taken into account are the station and position of the presenting part, moulding of the fetal head, comfort, morale and cooperation of the mother, as well as experience of the operator and the availability of the necessary equipments. ${ }^{1}$ Last few decades have witnessed rise in number of vacuum deliveries among instrumental deliveries. ${ }^{3-5}$ Established risk factors for requiring ventouse delivery include advanced maternal age, high body mass index (BMI), epidural analgesia, and high birth weight. The aim of this study is to identify risk factors for unsuccessful instrumental delivery, and thus aid the accoucheur in difficult decision-making.

\section{METHODS}

A cohort of 29861 women with vertex-presenting, single, liveborn infants at term (37-42 completed weeks of gestation), aiming for vaginal delivery was identified over a 10-year period in a single tertiary obstetrics teaching center at Pune. Data regarding each woman's pregnancy, labor, and delivery were recorded by resident shortly after the birth, and were subsequently obtained from the record section of the hospital. Deliveries were classified according to the final mode of delivery. Out of these 29861 deliveries, 19831 (66.4\%) were vaginal deliveries. $8802(29.47 \%)$ were cesarean deliveries and $1228(4.1 \%)$ were instrumental deliveries. Among instrumental deliveries, $687 \quad(56 \%)$ were vacuum deliveries and $541(44 \%)$ were forceps deliveries (Table $1)$. In the present study, vacuum deliveries were carried out, when station of head was either at +1 or +2 . In seventy percent cases, vacuum was applied by junior consultant and thirty percent by resident doctor under supervision of the consultant. Approximately $65 \%$ of cases were primigravidas and remaining were multigravidas Unsuccessful vacuum deliveries were defined as those where ventouse was applied to the fetal head, but the eventual mode of delivery was cesarean delivery. The indications and procedures for vacuum delivery in our center are as defined in the operative vaginal delivery guidance from the Royal College of Obstetricians and Gynaecologists. Characteristics of the materno-fetal dyad were extracted from the hospital records, including maternal age (at time of delivery), BMI (at first trimester prenatal booking), parity (prior to delivery), ethnicity, and the birth weight of the infant. Birth weight was recorded to the nearest gram. Variables related to the delivery attempt were also noted: whether epidural analgesia was used prior to the delivery attempt, the length of time between diagnosis of second stage and the time of delivery (time fully dilated), and the instrument selected. Gestational age was recorded to the nearest week. Only those cases where birth occurred within the interval 37- 42 weeks completed gestation were included. No adjustment was made for infants found to be small or large for gestational age. No record of the station of the presenting part was available within our dataset. However, to our knowledge, no delivery was carried out where the presenting part was above the level of the ischial spines. The seniority of accoucheur attempting delivery was also recorded, and classified into four types, the Postgraduate and senior residents, Assistant Professors, Associate Professor and Professors as classified by the MCI (Medical Council of India) teacher's eligibility criteria.

\section{Statistical analysis}

In present statistical analyses, group-wise comparisons were carried out using either Student's t-test, and Pearson's chi-squared test for categorical data. Several multivariate regression models were also fit, Findings were considered statistically significant at an alpha level of 0.05. All data analysis was conducted using the $\mathrm{R}$ statistical software package. Failed vacuum delivery was modeled using logistic regression with the following covariates: birth weight, maternal age, ethnicity, maternal BMI, seniority of accoucheur, parity, delivery during daylight hours, and use of epidural analgesia. Separate analyses were run for two cohorts: the full cohort, and a case-control subset. The full cohort comprised all successful and unsuccessful ventouse deliveries.

\section{RESULTS}

During the study period of 10 years, there were 29861 deliveries, of which $19831 \quad(66.4 \%)$ were vaginal deliveries. $8802(29.47 \%)$ were cesarean deliveries and $1228(4.1 \%)$ were instrumental deliveries. Among instrumental deliveries, $687(56 \%)$ were vacuum deliveries and 541 (44\%) were forceps deliveries (Table 1).

In the present study, vacuum deliveries were carried out, when station of head was either at +1 or +2 . In seventy percent cases, vacuum was applied by junior consultant and thirty percent by resident doctor under supervision of the consultant. Approximately $65 \%$ of cases were primigravidas and remaining were multigravidas. With 
increasing parity, the incidence of vacuum delivery decreased (Table 2).

Table 1: Information regarding mode of delivery during study period.

\begin{tabular}{|lll|}
\hline Mode of delivery & No. of cases $(\mathbf{n = 2 9 8 6 1 )}$ & $\%$ \\
\hline Vaginal delivery & 19831 & 66.41 \\
\hline LSCS & 8802 & 29.47 \\
\hline Ventouse delivery & 687 & 2.3 \\
\hline Forceps & 541 & 1.8 \\
\hline
\end{tabular}

Table 2: Paritywise distribution of ventouse deliveries.

\begin{tabular}{|lll|}
\hline Gravida & No. of cases $(\mathrm{n}=687)$ & $\%$ \\
\hline G1 & 447 & 65.06 \\
\hline G3 & 221 & 32.16 \\
\hline G4 and above & 7 & 1.74 \\
\hline
\end{tabular}

In $54 \%$ of cases, vacuum was applied for prophylactic indications and for therapeutic indications in $46 \%$ of cases. Vaginal Birth after Cesarean section and maternal exhaustion were the commonest indications for vacuum application (Table 3).

Table 3: Indications for ventouse delivery.

\begin{tabular}{|lll|}
\hline Indication & No. of cases $(\mathrm{n}=687)$ & $\%$ \\
\hline Previous LSCS & 146 & 21.25 \\
\hline Heart disease & 48 & 6.98 \\
\hline $\begin{array}{l}\text { Severe hypertension } \\
\text { Severe anemia }\end{array}$ & 107 & 15.57 \\
\hline $\begin{array}{l}\text { Maternal exhaustion } \\
\text { /poor maternal } \\
\text { bearing down }\end{array}$ & 21 & 3.05 \\
\hline Rigid perineum & 76 & 31.87 \\
\hline Foetal distress & 61 & 11.06 \\
\hline Second of the twins & 9 & 8.87 \\
\hline
\end{tabular}

Six percent cases had either perineal or cervico vaginal tears that required suturing. There were three cases of third degree perineal tear.

Table 4: Maternal morbidity in ventouse delivery

\begin{tabular}{|lll|}
\hline $\begin{array}{l}\text { Maternal morbidity } \\
\text { Extension of } \\
\text { episiotomy }\end{array}$ & 27 & No. of cases $(\mathrm{n}=687)$ \\
\hline Vaginal laceration & 12 & 1.74 \\
\hline $\begin{array}{l}\text { Cervical laceration } \\
\text { Postpartum } \\
\text { hemorrhage }\end{array}$ & 3 & 0.43 \\
\hline $\begin{array}{l}\text { Need for blood } \\
\text { transfusion }\end{array}$ & 11 & 1.6 \\
\hline $\begin{array}{l}\text { Episiotomy wound } \\
\text { complications }\end{array}$ & 9 & 0.87 \\
\hline
\end{tabular}

Six cases required blood transfusion for atonic postpartum hemorrhage following vacuum delivery. Nine cases had episiotomy wound related complications in the form of wound dehiscence requiring suturing (Table 4).

Table 5: Neonatal morbidity and perinatal mortality.

\begin{tabular}{|lll|}
\hline Morbidity/ mortality & No. of cases $(\mathbf{n}=687)$ & $\%$ \\
\hline Birth asphyxia & 14 & 2.03 \\
\hline Birth trauma & 2 & 0.29 \\
\hline Meconium aspiration & 4 & 0.58 \\
\hline NICU admissions & 17 & 2.47 \\
\hline Still births & 1 & 0.14 \\
\hline Neonatal deaths & 3 & 0.43 \\
\hline
\end{tabular}

Twenty babies (2.9\%) had morbidity in the form of birth asphyxia, meconium aspiration or birth trauma. There were three neonatal deaths and one fresh still birth (Table 5).

Table 6: All cases of successful vacuum delivery compared to all cases of vacuum delivery, using multivariate analysis with a binomial logistic regression model.

\begin{tabular}{|ll|}
\hline Variable & Odds Ratio $(95 \%$ CI) \\
\hline $\begin{array}{l}\text { Rotation (not required) } \\
\text { Rotation (required) }\end{array}$ & $\begin{array}{l}\text { Ref } \\
1.32(1.01-2.26) *\end{array}$ \\
\hline $\begin{array}{l}\text { Birth weight (per 100g } \\
\text { increase) }\end{array}$ & $1.01(1.06-1.12) \dagger$ \\
\hline Time fully dilated & $1.01(1.00-1.01) \dagger$ \\
\hline Parity & $0.89(0.76-1.21)$ \\
\hline Maternal age & $1.01(0.99-1.06)$ \\
\hline Day shift & Ref \\
Night shift & $0.96(0.73-1.26)$ \\
\hline No epidural & Ref \\
Epidural & $1.21(0.94-1.66)$ \\
\hline
\end{tabular}

Model coefficients are expressed as odds ratios and 95\% confidence intervals (CI). Associations that meet the threshold for statistical significance (alpha level $=0.05$ ) are shown in boldface. ${ }^{*} \mathrm{p}<0.05, \dagger \mathrm{p}<0.001, \mathrm{CI}$, confidence interval

Out of Six hundred and eighty-seven ventouse deliveries of vertex presenting, single, term infants were attempted, 38 were unsuccessful (5.5\%). Increased birth weight $(\mathrm{OR}=1.11 \mathrm{p}<0.001)$, second-stage duration $(\mathrm{OR}=1.01$ $\mathrm{p}<0.001)$, rotational delivery $(\mathrm{OR}=1.52 \mathrm{p}<0.05)$ and use of ventouse versus forceps $(\mathrm{OR}=1.33 \mathrm{p}<0.05)$ were associated with unsuccessful outcome. Table 6 shows the results of the regression analysis for the full cohort.

Table 7 shows the results of the regression analysis for the case-control subset. Increased birth weight $(\mathrm{p}<0.001)$ and longer time fully dilated $(\mathrm{p}<0.001)$ remain statistically significant, even after accounting for interaccoucheur variability.

The need for rotation and the instrument used are no longer significant at the 0.05 level. 
Table 7: Influence of parameters known to the accoucheur prior to instrumental delivery attempt on birth weight.

\begin{tabular}{|ll|}
\hline Variable & Odds Ratio $(95 \% \mathrm{CI})$ \\
\hline Gestational age & $4.88(4.35-5.48)^{*}$ \\
\hline Parity & $1.37(1.11-1.69) \dagger$ \\
\hline Maternal BMI & $0.10(0.10-1.20)$ \\
\hline Maternal age & $0.98(0.96-1.01)$ \\
\hline
\end{tabular}

Multivariate analysis was performed using a logistic regression model. Model coefficients are expressed as odds ratios and $95 \%$ Cs. ${ }^{*} \mathrm{p}<0.001,{ }^{\dagger} \mathrm{p}<0.01$. CI, confidence interval. Associations that meet the threshold for statistical significance (alpha level $=$ 0.05 ) are shown in boldface.

When inter accoucheur variability was controlled for, instrument selection and decision to rotate were no longer associated with vacuum delivery success. More senior accoucheurs (Associate Professor and Professors) had higher rates of unsuccessful deliveries $(12 \%$ v. $5 \%$, $\mathrm{p}<0.05$ ), but undertook more complicated cases Figure 1 Cesarean delivery in the second stage without prior attempt at vantouse delivery was associated with higher birth weight $(\mathrm{OR}=1.07 \mathrm{p}<0.001)$, increased maternal age $(\mathrm{OR}=1.03 \mathrm{p}<0.01)$, and epidural analgesia $(\mathrm{OR}=1.46$ $\mathrm{p}<0.001)$.

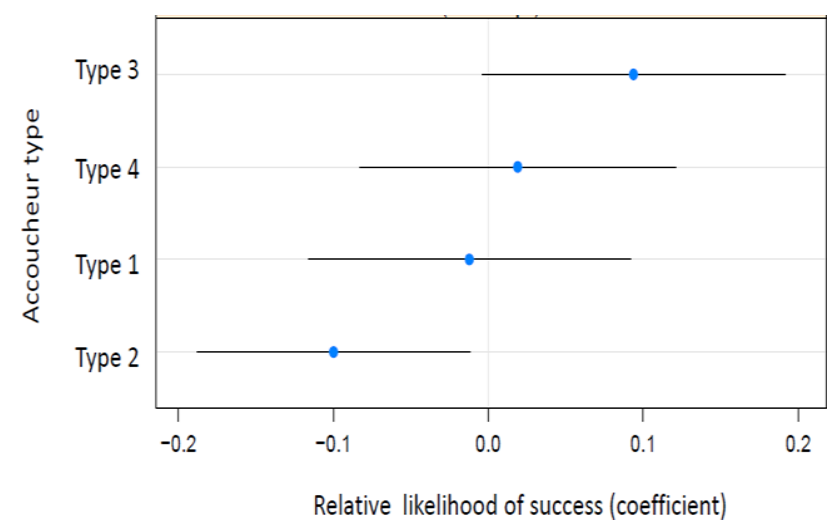

Figure 1: Likelihood of success in instrumental delivery classified by accoucheur type.

\section{DISCUSSION}

Historically, the obstetric forceps, which preceded the development of the vacuum cup by many decades, was the primary instrument used. However, more recently this has been superseded by the vacuum in some countries ${ }^{3}$. In the United Kingdom, there has been an increasing use of vacuum compared to forceps. ${ }^{4,5}$

The most common complications of assisted vaginal birth for the mother involve perineal trauma. Life-threatening complications are very rare. ${ }^{6}$ Subgaleal hematoma, which is quoted as occurring in 1-4\% of babies born with vacuum extraction, is the most important life-threatening complication of this mode of delivery. ${ }^{7-9}$
In present study, it was observed that increased birthweight and increased duration of second stage are strongly associated with lack of success in vacuum delivery in both the unmatched and case control analyses. Use of ventouse rather than forceps, and attempted rotation of the fetal head are associated with lack of success in the unmatched analysis only. One possible interpretation of the associations between instrument selection, rotation, and instrumental delivery outcome is that their influence may be operator-dependent. It is recognized that fetal head malposition in the second stage is a risk factor for adverse labor outcomes. ${ }^{11,12}$ While rotational instrumental delivery in our study had a higher rate of failure than non-rotational delivery, this was not the case for individual experienced operators, suggesting that more extensive experience of operative vaginal delivery would benefit trainee obstetricians. Although previous studies have concluded, as we do here in the full cohort analysis, that overall forceps delivery is more likely to achieve successful vaginal delivery than ventouse there is also evidence that operator preference for a particular instrument can affect the delivery outcome. ${ }^{13-17}$ However, rotation of the fetal head is considered a controversial procedure by many obstetricians, despite data showing low complication rates. ${ }^{18-20}$ Although more experienced accoucheurs had the highest unadjusted rates of unsuccessful instrumental attempts, this is likely to be because more difficult deliveries are usually handled by more senior obstetricians. After adjusting for birth weight and the need for rotation, junior obstetrics trainees had the highest adjusted rates of unsuccessful instrumental delivery, indicating that increased training and experience are imperative.

The main limitations of our study include the difficulty in classifying deliveries where sequential instruments were used, and the inability from our database to identify a small number of babies presenting in the occipitoposterior position who may have been delivered by instrument without rotation. Additionally, is possible that the longer time in second stage during unsuccessful instrumental deliveries may be partially explained by the extra time required to perform cesarean delivery, but we are unable to distinguish this possibility from a clinical effect of having a prolonged second stage using the data available.

In present study, it was demonstrated that once the need for instrumental delivery has been determined, the factors involved are reduced to a simple problem of mass and orientation to achieve delivery. Birth weight is difficult to estimate prior to delivery; however, it is the major determinant of likelihood of success. Continued training in instrumental delivery for obstetricians is invaluable, as our study demonstrates significant improvement in success rates with increasing experience, ability to select the appropriate instrument, and ability to rotate the fetal head. Future research could focus on better methods of 
birth weight prediction, and on safe, effective training strategies for resident obstetricians.

Funding: No funding sources Conflict of interest: None declared

Ethical approval: The study was approved by the Institutional Ethics Committee

\section{REFERENCES}

1. Mahony F, Hofmeyr GJ, Menon V. Choice of instruments in assisted vaginal delivery. Cochrane Database Syst Rev. 2010;11:CD005455.

2. Department of health. Statistical Bulletin. Maternity Statistics England 2003-2004. London. HMSO;2004.

3. Bofill JA, Parr KG, Roberts WF, Martin RW, Morrison JC, Rust OA. Forceps and vacuum delivery: A survey of North American residency programs. Obstet Gynaecol. 1996;88(4Pt1):622-5.

4. O Connell SW, Lindow M. Trends in obstetric care in Unite Kingdom. J Obstet Gynecol. 2000;20:592-3.

5. Patel RR, Murphy DJ. Forceps delivery in modern obstetrics practice. BMJ. 2004;328:1302-5.

6. Lewis G, Drife J. Why do mothers die? 1997-99: The fifth report of the Confidential Enquiries into Maternal Deaths in the United Kingdom. London: RCOG Press; 2001. Available at http://www.cemd.org.uk/reports/cemdrpt.pdf

7. Vacca A. Vacuum-assisted delivery. Best Pract Res Clin Obstet Gynaecol. 2002;16(1):17- 30.

8. Information and Statistics Division. Operative vaginal deliveries. Available at http://www.isdscotland.org/isd/info3.jsp?pContentID $=2152$ andp_applic $=$ CCCandp_serv

9. Towner D, Castro MA, Eby-Wilkens E, Gilbert WM. Effect of mode of delivery in nulliparous women on neonatal cranial injury. New Engl J Medic. 1999;341(23):1709-14.

10. Milkovasky P, Watson WJ, Obstetric vaccum extraction: State of art in the new millennium. Obstet Gynaecol Surv. 2001;56(11):736-51.

11. Senecal J, Xiong X, Fraser WD. Effect of fetal position on second-stage duration and labor outcome. Obstet Gynecol. 2005;105(4):763-72.
12. Al-Suhel R, Gill S, Robson S, Shadbolt B. Kjelland's forceps in the new millennium. Maternal and neonatal outcomes of attempted rotational forceps delivery. Aust N Z J Obstet Gynaecol. 2009;49(5):510-4.

13. Tempest N, Hart A, Walkinshaw S, Hapangama D. A re-evaluation of the role of rotational forceps: retrospective comparison of maternal and perinatal outcomes following different methods of birth for malposition in the second stage of labour. BJOG. 2013;120(10):1277-84.

14. O'Mahony F, Hofmeyr GJ, menon V. Choice of instruments for assisted vaginal delivery. Cochrane Database Syst Rev. 2010;(11):CD005455.

15. Ben-Haroush A, Melamed N, Kaplan B, Yogev Y. Predictors of failed operative vaginal delivery: a single-center experience. Am J Obstet Gynecol. 2007;197(3):308 e1-8 e5.

16. Abenhaim HA, Morin L, Benjamin A, Kinch RA. Effect of instrument preference for operative deliveries on obstetrical and neonatal outcomes. Eur J Obstet Gynecol Reprod Biol. 2007;134(2):164-8.

17. Dhanjal, MK, Kenyon, A. Scientific Impact Paper No. 34: Induction of labour at term in older mothers. UK. RCOG. 2013.

18. Al-Kadri H, Sabr Y, Al-Saif S, Abulaimoun B, Ba'Aqeel H, Saleh A. Failed individual andsequential instrumental vaginal delivery: contributing risk factors and maternal-neonatal complications. Acta Obstet Gynecol Scand. 2003;82(7):642-8.

19. Gopalani S, Bennett K, Critchlow C. Factors predictive of failed operative vaginal delivery. Am J Obstet Gynecol. 2004;191(3):896-902.

20. Sheiner E, Shoham-Vardi I, Silberstein T, Hallak M, Katz M, Mazor M. Failed vacuum extraction. Maternal risk factors and pregnancy outcome. J Reprod Med. 2001;46(9):819-24.

Cite this article as: Shinde KK, Karale A, Shekhawat G. Factors influencing the likelihood of vacuum delivery success. Int J Reprod Contracept Obstet Gynecol 2017;6:3818-22. 